\title{
LAS NEURONAS ESPEJO EN EL NEUROMARKETING: UNA ESTRATEGIA PELIGROSA CUANDO NO SE APLICAN NORMAS ÉTICAS
}

\section{Mirror Neurons in Neuromarketing: A Dangerous Strategy When No Applying Ethical Standards}

\section{Manuel Madé-Zabala}

Instituto Tecnológico de Santo Domingo (INTEC), República Dominicana

Correo-e: manuelmade@gmail.com ORCID: https://orcid.org/0000-0002-0097-6105

Recibido: 12/6/2019 • Aprobado: 25/7/2019

Cómo citar: Madé-Zabala, M. (2019). Las neuronas espejo en el neuromarketing: una estrategia peligrosa cuando no se aplican normas éticas. Ciencia y Sociedad, 44(3), 25-31. https://doi.org/10.22206/cys.2019.v44i3.pp25-31

Resumen

Los avances en las investigaciones neurocientíficas, en pocos años, no más de dos décadas, están teniendo un impacto importante en un amplio espectro de la investigación científica humana. Cada descubrimiento en el complejo tejido neuronal humano-animal, que refleja alguna interacción endógena o exógena a él, genera nuevas formas de aproximaciones científicas. Este ensayo aborda las neuronas espejos como uno de los descubrimientos más importante en el campo de la neurociencia, con significativas aplicaciones en el estudio científico del marketing, práctica que ha adoptado el nombre de neuromarketing. Por otra parte, presenta el valor que le confiere a la investigación neurocientífica y que apoya el desarrollo humano, siempre que se tomen en consideración normas éticas que regulen el uso de aplicaciones que degraden lo humano. Además, analiza como las ONG, las religiones y las empresas incorporan técnicas que tienen explicaciones fundamentadas en la forma cómo reaccionan las neuronas espejos, $\mathrm{y}$ vaticina los peligros que pueden desencadenar las malas prácticas llevada a cabo en un mercado competitivo. Culmina con una invitación a la reflexión ética sobre las aplicaciones de la neurociencia para generar consumo y crear necesidades absurdas en los consumidores, solo por vender.

Palabras clave: marketing; consumidor; neurobiología; ética de la ciencia; cerebro.

\begin{abstract}
Advances in neuroscientific research, in a few years, no more than two decades, are having an important impact on a broad spectrum of human scientific research. Every discovery in the complex human-animal neuronal tissue that reflects some endogenous or exogenous interaction with it emerges new forms of scientific approaches to such findings. This essay makes an approach to the neurons mirrors as one of the most important discoveries in the field of neuroscience with significant applications in the scientific study of marketing, this practice that has adopted the name of "neuromarketing". On the other hand, it assumes the value that neurons mirrors adds to the neuroscientific research that supports human development, if ethical norms that regulate the use of applications that degrade the human are taken into consideration. In addition, this work analyzes how NGOs, religions and companies integrate techniques that have explanations based on the way neurons react, and predicts the dangers that can trigger the bad practices carried out in a competitive market. It concludes with an invitation to ethical reflection on the applications of neuroscience only for produce consumption and create absurd needs in consumers, just to sell.
\end{abstract}

Keywords: Marketing; Consumer; Neurobiology; Ethics of science; Brain. 
Somos criaturas sociales. Nuestra supervivencia depende de entender las acciones, intenciones y emociones de los demás. Las neuronas espejo nos permiten entender la mente de los demás, no sólo a través de un razonamiento conceptual sino mediante la simulación directa. Sintiendo, no pensando.

\section{G. Rizzolatti}

\section{Introducción}

El descubrimiento de las "neuronas espejos" ha abierto el camino de nuevas investigaciones sobre el comportamiento humano en relación con la información que procesa su cerebro cuando está frente a algún fenómeno. La "alarma que sonó" al demostrarse la existencia de unas neuronas que podían mimetizar los movimientos de su entorno, aun estando en un cuerpo - motriz - en reposo (Rizzolatti \& Craighero, 2004), ha despertado la curiosidad de los neurocientíficos ¿Qué haremos con este descubrimiento? O ¿cuál será el próximo paso? Mientras los especialistas en neurociencia profundizan en los laboratorios al respecto haciendo nuevos hallazgos, el marketing, hoy por hoy, es tratado como una ciencia en la que entran en juego un grupo de factores metodológicos que resultan de estudios científicos — duro- para llegar a los individuos con la esperanza de configurarles el "metaconciente" y hacerlos más susceptibles al consumo de cierto producto o marca consumidores, en fin, hackear el cerebro del consumidor. Tales ambiciones son cada vez más alcanzables con la identificación de aquellas actividades que son sensibles a las neuronas espejos.

La competencia en el marketing, por lograr que los consumidores sean seducidos por los productos, ha llevado a los diferentes mercados al "límite", usando técnicas neurológicas vanguardistas, fundamentadas en la esperanza de que el cerebro de los consumidores esconde informaciones sobre sus preferencias reales (Ariely \& Berns, 2010). Ya no se podría hablar del arte del mercadeo, sino de la ciencia del mercadeo. No existe ninguna ingenuidad en el marketing que realizan las grandes compañías, están muy bien estudiados los consumidores desde la ciencia social, la estadística, la psicología, la ciencia económica, la neurociencia, etc.

El éxito o el fracaso del marketing en la actualidad pueden preverse en gran medida, y una de las pretensiones de este breve ensayo académico es analizar el impacto que podría tener el estudio de las neuronas espejos para efectuar un "marketing dirigido" que capte la atención inconsciente de los consumidores. En segundo lugar, veremos cómo este descubrimiento nos revela por qué han tenido tanto éxito algunas $\mathrm{ONG}$, las religiones y algunas empresas. Y para concluir, cerraremos con la interrogante sobre ¿qué se puede decir desde la ética sobre el uso de la neurociencia para fines mercadológicos?

\section{El marketing de laboratorio}

El título de este acápite responde al neuromarketing, porque la mayor parte de sus investigaciones se producen en los laboratorios, y no solo en laboratorios informáticos o talleres gráficos tradicionales, sino laboratorios de biología y de neurociencia. Las técnicas y tecnología que usan los laboratorios de neurociencia a merced del marketing, es la $\mathrm{I}+\mathrm{D}+\mathrm{i}$ (Investigación Desarrollo e Innovación) del marketing más vanguardista.

El marketing tradicional ha usado muchas técnicas y disciplinas científicas para llegar a los usuarios como lo es la estadística, la sociología, la economía, el arte, etc., pero todas estas técnicas, aunque tienen su efectividad y todavía se siguen usando, van quedando obsoletas con la aparición del neuromarketing (o más bien son reforzadas), ahora se ha cruzado la valla, se ha pasado a un nivel "metainvestigativo" donde entra en juego la neurociencia, el estudio del cerebro en tiempo real con el consumidor.

La década del noventa fue declarada como "Década del Cerebro” por el Congreso de los Estados Unidos. 
Esta iniciativa, que involucró importantes inversiones destinadas a la investigación en el ámbito de las neurociencias, fue imitada por la Comunidad Europea y algunos países asiáticos, entre ellos, Japón, China y la India; así lo declara Braidot, experto en neuromarketing (2009).

La “Década del Cerebro" sucede a la "Década del Espacio" (que dio lugar a numerosas innovaciones en materia de productos) y precede a "Década del Comportamiento” (2000-2010), que impulsa las investigaciones en ciencias de la conducta y sociales (que también son de enorme relevancia para la gestión del marketing) (Braidot, 2009).

El neuromarketing puede definirse como una disciplina de avanzada, que investiga y estudia los procesos cerebrales que explican la conducta y la toma de decisiones de las personas. Estos procedimientos abarcan todos los campos de acción del marketing tradicional: inteligencia de mercado, diseño de productos y servicios, comunicaciones, precios, posicionamiento, branding, targeting, canales y ventas (Braidot, 2009).

Se tiene conocimiento de que muchas compañías, como Pepsi y Coca Cola, han realizado estudios neurológicos para estudiar al consumidor y que esta tendencia no parará. Por tal razón, todo nuevo descubrimiento que tenga que ver con el comportamiento humano será de interés para las empresas que quieren posicionar un producto; la pregunta que nos formulamos es ¿en qué contribuirá el descubrimiento de las neuronas espejo a este movimiento mercantilista?

\section{Neuronas sociales}

Todo comenzó en 1996 cuando:

el equipo de Giacomo Rizzolatti, de la Universidad de Parma (Italia), estaba estudiando el cerebro de monos cuando descubrió un curioso grupo de neuronas. Las células cerebrales no sólo se encendian cuando el animal ejecutaba ciertos movimientos, sino que, simplemente con contemplar a otros hacerlo, también se activaban. Se les llamó neuronas espejo o especulares (Boto, 2005, párr. 1).

El sistema de espejo hace precisamente eso, te pone en el lugar del otro. "La base de nuestro comportamiento social es que exista la capacidad de tener empatía e imaginar lo que el otro está pensando", dijo Rizzolatti en una entrevista (Boto, 2005, párr. 5). Según estas conclusiones, podemos apreciar que el cerebro funciona como un Bluetooth con relación a los otros cerebros, que se activa con la señal que emiten otros cerebros $\mathrm{u}$ otros individuos, pero con la cualidad que comienza a descargar las informaciones de su alrededor automáticamente.

Está claro para los neurocientíficos que existe una gran diferencia entre lo que nos dicen las personas en una encuesta y lo que se puede monitorear mediante las instrumentaria y artefactos que poseen los laboratorios de neurociencia, con los cuales se puede interpretar en un alto porcentaje qué es lo que llama más la atención de los consumidores, siendo que gran parte de las actividades humanas se gestan en el subconsciente del cerebro. Esto puede hacerse con conocimiento de marca y en test a ciegas, tal como lo hizo Read Montagne ${ }^{1}$ en Estados Unidos con Coca Cola y Pepsi (citado por Braidot, 2005, p. 19).

Manipular esa capacidad de interacción social, conduciéndola al consumo, sería lo ideal para el marketing. Un ejemplo que nos plantea Braidot (2009, pp. 17,18) es que "mediante la técnica de biofeedback 5 se puede observar en el monitor de un ordenador la ausencia o presencia de emociones, como así también su intensidad, mientras un participante visualiza un comercial o experimenta con un producto". Así podría observarse el comportamiento de las neuronas espejos frente a nuestro

1. Read Montague es un especialista en neurociencias aplicadas. Dirige el Human Neuroimaging Laboratory del Baylor College de Medicina, en Houston. 
proyecto mercadológico y evaluar cuál sería su éxito o fracaso.

Nos dice Rizzolatti (Boto, 2005), las neuronas espejos son "neuronas sociales", esta cualidad la podríamos manipular a través de la elaboración o presentación de producto al cual estas neuronas tengan alta sensibilidad, es decir, monitorizar cuál es el nivel máximo de sensibilidad de estas neuronas y a partir de esta respuesta desarrollar productos más subjetivos.

\section{Las neuronas espejo en el marketing}

Con base en nuestra hipótesis plateada, es de considerar algunas promociones que han hecho instituciones con el fin de provocar nuestra sensibilidad emocional para lograr seducirnos e involucrarnos en sus proyectos, que pueden ser sociales, activistas, religiosos, políticos, campañas de promoción, etc. Por consiguiente, las reacciones que persiguen tales instituciones podríamos asociarlas con el comportamiento que han descubierto en las neuronas espejos (empatía, comprensión, vivencia emocional de otras personas, etc.).

Las organizaciones no gubernamentales (ONG), como las conocemos, en su mayoría, tratan de llevar proyectos sociales sin fines de lucros. Lograr que las personas contribuyan a las causas humanitarias o ambientales no es tarea fácil, hay que recurrir a la sensibilidad y la empatía humana para poder sostener la logística de esas instituciones. El camino para lograr captar la atención es el marketing publicitario que se centra en el tipo de proyecto que se está llevando a cabo. Algunas imágenes y videos bien seleccionada producen ciertas conmociones empáticas en los observadores que le hacen reaccionar (casi) de forma automática. Veamos algunos ejemplos: a) Las ONG y los atavismos

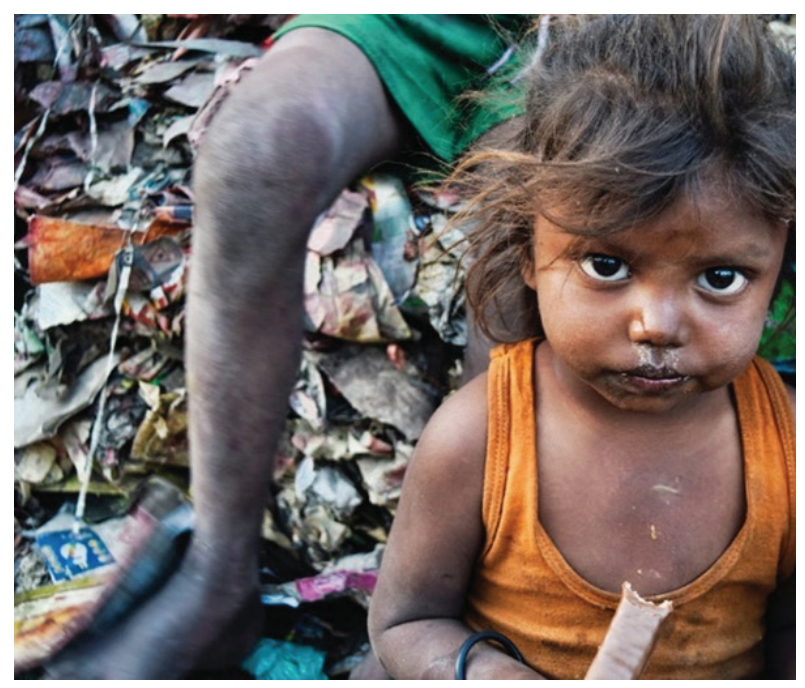

Ilustración 1. Imagen extraída de Pixabay (2019).

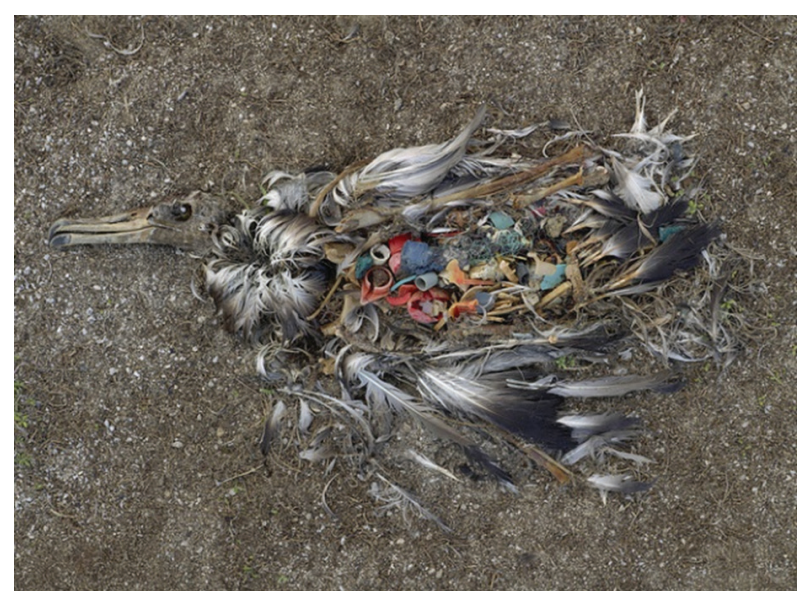

Ilustración 2. Foto Chris Jordan (2009).

Estas imágenes que presentamos responden a las estrategias de captación de atención que pueden usar algunas ONG y el activismo ambientalista. Se puede notar que poseen características del imaginario social que generan mayor sensibilidad, que tan pronto las vemos nos activan el cerebro, de tal manera que podemos reaccionar empáticamente frente a la causa que se quiere promover. 


\section{b) Las religiones}

Históricamente, las religiones han demostrado poseer una gran capacidad para dinamizar y lograr la atención masiva de las personas. Las esculturas, la pintura, los gestos, el discurso, el lenguaje, etc., han modificado la forma de ver el mundo de generaciones enteras. A todo esto, la pregunta quizás irreverente sería ¿existe alguna ingenuidad en todo esto? ¿Ha habido algunas mutaciones neuronales en esas generaciones de fieles religiosos? ¿Tendrán alguna participación las neuronas espejos en la configuración cerebral de estos individuos? Estas preguntas — quizás necias - pueden tener explicaciones muy cercanas a la realidad, abordándolas desde los resultados que se pueden obtener en los laboratorios de neurociencia e identificar algunas de las razones que hicieron que el razonamiento humano no fuera capaz de evitar esta dinámica social asumiéndola hasta nuestros tiempos, y ver qué técnicas funcionan más para mantener el statu quo, ya que la capacidad de asimilar los símbolos como especies simbólicas es parte evolutiva en nuestros cerebros (Deacon, 1998).

\section{c) Las empresas}

Desde hace tiempo conocemos los famosos "mensajes subliminales" que se hacían en los cines para lograr que los cinéfilos compraran refrescos y golosinas, y que hoy pululan por el Internet cantidades de estudios e imágenes, canciones y videos (algunos ingenuos, pero otros un poco más riguroso). A todo esto, le agregamos la incursión de las marcas de compañías en los videos juegos, de tal manera que estamos ahogados por las empresas que quieren posicionarse en primer lugar del mercado. Con toda esta experiencia del marketing que tienen las empresas y su disposición a seguir indagando al respecto, hacer estremecer las neuronas espejo con una publicidad de base científica es una posibilidad innegable.
Ver a Coca Cola involucrada en campañas humanitarias, a Red Bull apoyando el arte urbano y el deporte extremo, y un listado inmenso de marcas apoyando los temas "medios ambientales" que son los que más sensibilidad están causando en el mundo, aun habiendo empresas de alta contaminación involucradas en ellos, nos hace pensar que algo extraño anda en medio de este marketing que no tiene que ver con el humanismo o el cuidado del planeta. Dice Moraño (2010):

Si transportamos este descubrimiento al mundo del marketing, concretamente al del neuromarketing, encontramos autores como Martin Lindstrom que en su libro compradicción (Buyology) asocia el éxito comercial del iPod de la marca Apple, el videojuego Guitar Hero o el de un teléfono de la marca Bang \& Olufsen a las neuronas espejo. (párr. 4)

Dudar de que los estudios que hacen las grandes compañías en los laboratorios neurológicos sean el boom de sus productos es ingenuo, puesto que ya hay empresas neurológicas que se dedican a estos estudios como la FKF Applied Research ${ }^{2}$. Estas empresas estudian al consumidor en laboratorios que disponen de todas las tecnologías de observación neurocientíficas.

Partiendo de las caracterizaciones que le han dado los neurocientíficos a las actividades que activan el funcionamiento de las neuronas espejos, numerosas dinámicas que vemos (y algunas en la que caemos), podemos decir que están relacionadas con ellas estrechamente.

\section{Ética y neuromarketing}

Manipular a los individuos estudiando su función cerebral y llevándolo a la compra compulsiva, nos lleva a una reflexión ética; especialmente por el sentido de sugestión de la libertad y el desconocimiento que puedan tener los consumidores al respecto.

2. http://www.fkfappliedresearch.com/ 
Presentamos algunas consideraciones éticas que se han hecho al respecto y que demuestran cómo los individuos están a la intemperie (Ariely \& Berns, 2010; traducidas por Monge, 2010):

a) Ausencia de regulación. "No existen organismos ni leyes que regulen la investigación de neuromarketing y deberían generarse" (párr. 8). Muchas de las investigaciones son realizadas bajo secreto empresarial para no revelar a los consumidores cómo les están invadiendo y se desate una revuelta social.

b) Gestión de las percepciones. “¿Cómo se tomará el público que la neurociencia haya sido utilizada para diseñar un producto? ¿Cómo lo presentarán las empresas? ¿Es ético ocultarlo?” (párr. 9). En esta parte la neurociencia debe tener cuidado, sin irnos a los extremos, podemos recordar qué pasó con la física nuclear después de la "bomba atómica”. Los seres humanos podemos asociar un tipo de ciencia con "peligro" fácilmente, por eso debería hacerse una divulgación seria sobre esta ciencia ante que lo hagan las malas promociones.

c) Las empresas no tienen por qué estar preocupadas por el mejor interés del consumidor. 'La maximización de los beneficios empresariales muchas veces entra en conflicto con los intereses de los consumidores" (párr. 10). El establecimiento de una empresa - como tal — se enfoca en generar riqueza, el consumidor para tales fines representa un sujeto-objeto, el cual se estudia para evaluar sus necesidades y crearle otras a través de experiencias sintéticas. La participación del consumidor debe ser de interés para la empresa no solo como el que "consume", sino como el "sujeto-humano".

El neuromarketing, desde esta óptica, es una forma invasiva a la vulnerabilidad del cerebro de las personas, y aquí ya no se podría hablar de "comprador compulsivo", sino de "vendedores compulsivos". No se trata de satisfacer necesidades solamente, es también una orientación al consumo irracional.
Varios estudios apuntan al peligro de esta dinámica materialista que afecta el bienestar social y humano (Bauer, Wilkie, Kim, \& Bodenhausen, 2012; Kasser, 2006).

Este ensayo es una invitación a pensar ¿qué pasa en el cerebro de los compradores "compulsivos"? ¿Realmente son compulsivos o hay una razón extrínseca a ello que lo ha hecho llegar a tal extremo? Aunque no todas las personas padecen de este comportamiento de forma patológica, se podría considerar que todos tenemos algo de compradores compulsivos, dependiendo de qué nos vendan y cómo nos los vendan. Entonces habría que identificar qué parte de nuestro cerebro ha sido afectada socialmente para que tengamos esa tendencia a comprar algunas cosas compulsivamente.

\section{Conclusión}

El descubrimiento de las neuronas espejos es el camino a una comprensión amplia sobre el desarrollo de nuestro comportamiento social. Con su hallazgo y funcionamiento como promotora del comportamiento social se han ido identificando algunos trastornos físicos, como el "autismo", para estudiarlo a profundidad y darle una aplicación médica a este descubrimiento.

A las neuronas espejos se les podría sacar provecho sin tener que dañar la imagen de una ciencia tan importante como la neurociencia, la cual no solo trata de descifrar los misterios del cerebro, sino que con sus explicaciones nos ayuda a identificar cuáles serían los tratamientos más factibles para algunas enfermedades, trastornos o comportamientos, en colaboración con otras ciencias para desarrollar fármacos que puedan mejorar dichas situaciones, o el desarrollo de artefactos tecnológicos que introducidos en el cerebro pueden estimular áreas del cerebro en diferentes casos, tanto de forma terapéutica como agregar potencialidades.

Mientras más se informa a la población, mejor es; menor información, mayor riesgo cuando se descubre 
la realidad. El marketing, si quiere beneficiarse de esta ciencia, tiene que hacer divulgación sobre sus investigaciones para que la gente sea consciente de su decisión a la hora de comprar. El cigarrillo, las drogas y el alcohol están regulados en muchos países y la gente sigue comprándolo, aunque está consciente de sus efectos nocivos a la salud, entonces ¿cuál es el temor de divulgar lo que se investiga en neuromarketing?

\section{Referencias}

Ariely, D., \& Berns, G. S. (2010). Neuromarketing: The hope and hype of neuroimaging in business. Nature Reviews. Neuroscience, 11(4), 284-292. doi: https://doi.org/10.1038/nrn2795

Bauer, M. A., Wilkie, J. E. B., Kim, J. K., \& Bodenhausen, G. V. (2012). Cuing Consumerism: Situational Materialism Undermines Personal and Social Well-Being. Psychological Science, 23(5), 517-523. doi: https://doi. org/10.1177/0956797611429579

Boto, A. (2005, octubre 19). Entrevista | «Las neuronas espejo te ponen en el lugar del otro». El País. Recuperado de https://elpais.com/diario/2005/10/19/futuro/1129672806_850215. html

Braidot, N. P. (2005). Neuromarketing: Neuroeconomía y negocios. Madrid, España. Puerto Norte-Sur.

Braidot, N. P. (2009). Neuromarketing: ipor qué tus clientes se acuestan con otro si dicen que les gustas tú? Barcelona, España. Gestión 2000.
Chris, J. (2009). Midway: Massage from the Gyre. Recuperado 18 de julio de 2019, de Chris Jordan website: http://www.chrisjordan.com/gallery/ midway/\#CF000478\%2019x25

Deacon, T. W. (1998). The symbolic species: The co-evolution of language and the brain (Norton paperback). New York, New York, EE. UU.: Norton.

Kasser, T. (2006). The high price of materialism. Cambridge, Reino Unido: MIT Press.

Monge, S. (2010). Problemas éticos del neuromarketing | Neuromarca. Recuperado 18 de julio de 2019, de Neuromarca website: http://neuromarca.com/ blog/problemas-eticos-neuromarketing/

Moraño, X. (2010). Neuronas espejo y neuromarketing | Marketing y Consumo. Recuperado 18 de julio de 2019, de https://marketingyconsumo. com/neuronas-espejo-y-neuromarketing.html

PixaBay. (2019). Niña pobre de la India. [Imagen gratis en Pixabay] Recuperado 18 de julio de 2019: https://pixabay.com/es/photos/pobres-india-pobreza-personas-2382641/

Rizzolatti, G., \&Craighero,L. (2004). TheMirror-Neuron System. Annual Review of Neuroscience, 27(1), 169-192. doi: https://doi.org/10.1146/ annurev.neuro.27.070203.144230

\section{Datos de filiación}

Manuel Madé-Zabala. Doctor en Lógica y Filosofía de la Ciencia, Universidad de Salamanca, Espańa. Sus líneas de investigación son el software libre en los procesos de enseñanza aprendizajes, tecnología educativa, filosofía de la ciencia y la tecnología, tecnologías cognitivas y análisis bibliométricos. Tiene publicado un artículo: "Aspectos pedagógicos y filosófico del software libre", su tesis doctoral con el título "Alfabetización TIC con software libre para una sociedad libre y sostenible: estudio de factibilidad en el contexto educativo de la República Dominicana” (en fase de edición). 


\section{Una Mirada desde}

lo Particular 